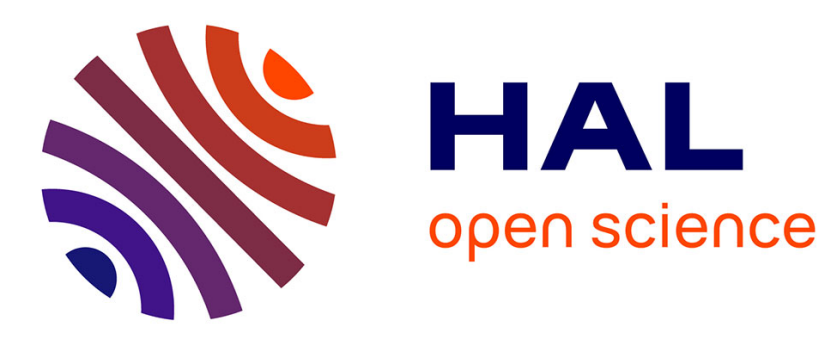

\title{
Twinning system selection in a metastable $\beta$-titanium alloy by Schmid factor analysis
}

Emmanuel Bertrand, Philippe Castany, Isabelle Péron, Thierry Gloriant

\section{To cite this version:}

Emmanuel Bertrand, Philippe Castany, Isabelle Péron, Thierry Gloriant. Twinning system selection in a metastable $\beta$-titanium alloy by Schmid factor analysis. Scripta Materialia, 2011, 64 (12), pp.11101113. 10.1016/j.scriptamat.2011.02.033 . hal-00926958

\section{HAL Id: hal-00926958 https://hal.science/hal-00926958}

Submitted on 13 Jan 2014

HAL is a multi-disciplinary open access archive for the deposit and dissemination of scientific research documents, whether they are published or not. The documents may come from teaching and research institutions in France or abroad, or from public or private research centers.
L'archive ouverte pluridisciplinaire HAL, est destinée au dépôt et à la diffusion de documents scientifiques de niveau recherche, publiés ou non, émanant des établissements d'enseignement et de recherche français ou étrangers, des laboratoires publics ou privés. 


\title{
Twinning system selection in a metastable $\beta$-titanium alloy by Schmid factor analysis
}

\author{
E. Bertrand, P. Castany, I. Péron, T. Gloriant \\ UMR CNRS 6226 Sciences Chimiques de Rennes, INSA Rennes, 20 Avenue des Buttes de \\ Coësmes, 35708 Rennes Cedex 7, France
}

\begin{abstract}
Electron backscattering diffraction and Schmid factor analysis were used to study the twinning variant selection in a Ti-25Ta-24Nb (mass\%) metastable $\beta$-titanium alloy. The two twinning systems $\left\{\begin{array}{lll}1 & 1 & 2\end{array}\right\}\left\langle\begin{array}{lll}1 & 1 & 1\end{array}\right\rangle$ and $\left\{\begin{array}{lll}3 & 3 & 2\end{array}\right\}\left\langle\begin{array}{lll}1 & 1 & 3\end{array}\right\rangle$ were observed. For each system the Schmid factor was shown to be a relevant parameter to determine the activated variant. Moreover, selection between the two twinning systems depends on the crystallographic orientation of the grain with respect to the tensile direction.
\end{abstract}

Keywords: Titanium alloy; Electron backscattering diffraction; Twinning; Schmid factor

Metastable $\beta$-titanium alloys can be elaborated with fully biocompatible $\beta$-stabilizer elements such as $\mathrm{Ta}, \mathrm{Nb}, \mathrm{Mo}$, etc. Their interesting mechanical properties make them good candidates for biomedical applications [1] and [2]. Theses alloys possess a non-ordered bcc structure and are subject to numerous deformation mechanisms: a stress induced martensitic transformation which can lead to a superelastic effect, slip and twinning [3] and [4].

Twinning is a common deformation mechanism in materials exhibiting a low stacking fault energy in hcp, fcc or bcc structures. In bcc structures $\left\{\begin{array}{lll}1 & 1 & 2\end{array}\right\}\left\langle\begin{array}{llll}1 & 1 & 1\end{array}\right\rangle$ is a well-known twinning system, but other twinning systems such as $\left.\begin{array}{lllllll}3 & 3 & 2\end{array}\right\}\left\langle\begin{array}{llll}1 & 1 & 3\end{array}\right\rangle$ have been observed in some metastable alloys subject to a martensitic transformation, like $\mathrm{Fe}-\mathrm{Ni}-\mathrm{C}$ or $\mathrm{Fe}-\mathrm{Be}$ [5]. In metastable $\beta$-titanium alloys both twinning systems $\left\{\begin{array}{llllll}1 & 1 & 2\end{array}\right\}\left\langle\begin{array}{llll}1 & 1 & 1\end{array}\right\rangle$ and $\left\{\begin{array}{lllll}3 & 3 & 2\end{array}\right\}\left\langle\begin{array}{llll}1 & 1 & 3\end{array}\right\rangle$ 
have been observed, depending on the alloy composition [6] and [7]. Each twinning system can be activated in 12 different ways, termed variants in this paper.

The Schmid law is commonly used to predict the activated slip system depending on the tensile direction compared with the crystallographic orientation of the crystal. Selection of the twinning variant can also be predicted by the Schmid law for materials exhibiting hcp or fcc structures, as reported in the literature [8] and [9]. Although it is well known that both slip and twinning occur in bcc titanium alloys, the objective of this paper was to confirm that twinning variant selection in each observed system obeys the Schmid law for a metastable $\beta$ titanium alloy (bcc). As several twinning systems can be observed in this kind of alloy a selection parameter between these twinning systems will also be established.

The metastable $\beta$-alloy composition chosen for this study is Ti-25Ta-24Nb (mass\%). The ingot was elaborated by cold crucible levitation melting (CCLM). It underwent homogenization annealing at $950^{\circ} \mathrm{C}$ for $20 \mathrm{~h}$, followed by a water quench. Each ingot was then cold rolled $(\mathrm{CR}=90 \%)$, after which a recrystallization annealing was applied at $850{ }^{\circ} \mathrm{C}$ for $0.5 \mathrm{~h}$, followed by a water quench in order to retain the $\beta$-phase microstructure at room temperature in its metastable state.

Before the recrystallization annealing flat tensile test specimens with a section of $3 \times 0.7 \mathrm{~mm}$ and a gage length of $15 \mathrm{~mm}$ were machined. The tensile direction was parallel to the rolling direction. Cyclic tensile tests, including strain increments of $0.5 \%$ followed by stress release, were carried out up to $5 \%$ at a strain rate of $10^{-4} \mathrm{~s}^{-1}$. The tensile tests were followed up to rupture. This mechanical test was used to characterize the superelastic effect due to stressinduced martensitic transformation occurring in this kind of alloy [4]. In addition, we observed that cyclic tensile tested specimens exhibit more twins compared with monotonic tensile tested specimens.

Electron backscattering diffraction (EBSD) studies were carried out in a JEOL JSM 6400 scanning electron microscope equipped with a TSL EBSD system. The samples were prepared by mechanical polishing to a "mirror finished" state. In titanium alloys mechanical polishing is known to induce important residual deformation in the surface layer that has deleterious effects on the quality of EBSD patterns. Chemical etching with a solution of $5 \%$ $\mathrm{HF}, 5 \% \mathrm{HNO}_{3}$ and $90 \% \mathrm{H}_{2} \mathrm{O}$ (vol.\%) was used to remove this surface layer.

The optical micrograph given in Figure 1a shows that the Ti-25Ta-24Nb alloy in the recrystallized state is composed of equiaxed grains with an average diameter of $50 \mu \mathrm{m}$. Figure $1 \mathrm{~b}$ shows that most of the grains were deformed by twinning during the tensile test. It should 
be stated here that the grains were also deformed by slip. However, slip could not be observed by the technique of EBSD used in this study.

Several twinned grains were characterized by EBSD and an example of the data obtained is given in Figure 2a. For each grain the orientations of the parent crystal and twins were determined from the Euler angles. The twinning system was then characterized from the poles belonging to the parent crystal and the twin. To ensure statistical significance about 20 grains in several zones of the tensile specimen were analyzed.

By way of illustration, two grains, denoted G1 and G2, and their twins, denoted T1 and T2, respectively, were located on the EBSD ma in Figure 2a. Each grain is deformed by several twins of the same variant of the same system. The twinning system activated in G1 is $\left\{\begin{array}{lll}1 & 1 & 2\end{array}\right\}$

$\left\langle\begin{array}{lll}1 & 1 & 1\end{array}\right\rangle$. In G2 the other twinning system, $\left\{\begin{array}{lll}3 & 3 & 2\end{array}\right\}\left\langle\begin{array}{lll}1 & 1 & 3\end{array}\right\rangle$, is activated. The coincidence site lattice (CSL) of the $\left\{\begin{array}{llllll}1 & 1 & 2\end{array}\right\}\left\langle\begin{array}{llll}1 & 1 & 1\end{array}\right\rangle$ twin was determined to be a $\Sigma 3$ boundary, which corresponds to a misorientation of $60^{\circ}$ around $\left\langle\begin{array}{lll}1 & 1 & 1\end{array}\right\rangle$ (Fig. 2b). For the twinning system $\left\{\begin{array}{lll}3 & 3 & 2\end{array}\right\}\left\langle\begin{array}{llll}1 & 1 & 3\end{array}\right\rangle$ the CSL boundary is $\Sigma 11$, which corresponds to a misorientation of $50.57^{\circ}$ around $\left\langle\begin{array}{llll}1 & 1 & 0\end{array}\right\rangle$ (Fig. 2c).

Twinning can be considered as the slip of partial dislocations, for example, in the $\left\{\begin{array}{lll}1 & 1 & 2\end{array}\right\}$ $111\rangle$ twinning system the Burgers vector is $a / 6\left\langle\begin{array}{lll}1 & 1 & 1\end{array}\right\rangle$. An important difference between twinning and slip of perfect dislocations is the polarity of twinning. This means that the slip of a partial dislocation in the opposite sense to the twinning direction (anti-twinning direction) would not produce a twin, since it would be energetically unfavorable [10]. As a consequence, activated variants under uniaxial tensile stress will be different from those activated under uniaxial compression stress in the same direction. In order to apply the Schmid law and distinguish the variants that can be activated during a tensile test the sign of the indices of each variant must be defined in accordance with the usual criteria [10] in order to distinguish between variants leading to elongation or compression along the applied stress direction. The set of indices used is given in Table 1 .

The Schmid factor (SF) is defined similarly to slip as:

\section{$\mathrm{SF}=\cos \lambda \cos \phi$}

where $\lambda$ and $\phi$ are the angles between the tensile direction and the normal to the twinning plane and the twinning direction, respectively. The values of $\lambda$ and $\phi$ are taken between $0^{\circ}$ and $180^{\circ}$ in order to obtain SF values between -0.5 and 0.5 . Using this convention a variant whose SF is positive leads to elongation along the tensile direction and will accommodate 
tensile stress. The activation of a variant whose SF is negative would lead to contraction along the tensile direction and will not be observed during a tensile test.

The tensile direction is marked in each grain reference frame in order to assess the value of $\lambda$ and $\phi$. In grains G1 and G2 the variants possessing an absolute value of SF higher than 0.3 are given in Table 2 and Table 3. It was considered that no variant whose SF is lower than 0.3 can be activated, which was confirmed for every grain analyzed. In G1 the experimentally observed variant has the highest positive value among the variants of the $\left\{\begin{array}{lll}1 & 1 & 2\end{array}\right\}\left\langle\begin{array}{llll}1 & 1 & 1\end{array}\right\rangle$ system, but two variants of the twinning system $\left.\begin{array}{llllll}3 & 3 & 2\end{array}\right\}\left\langle\begin{array}{lll}1 & 1 & 3\end{array}\right\rangle$ have a similar SF (Table 2). In $\mathrm{G} 2$ the activated variant is the only one possessing a positive SF higher than 0.4 (Table 3). In the other grains studied the activated variant generally possesses a SF between 0.4 and 0.5 ; the minimum SF value that led to the activation of twinning was 0.38. As predicted, no variant with a negative SF was observed. When both twinning systems exhibit a variant with a high SF $\left\{\begin{array}{lll}1 & 1 & 2\end{array}\right\}\left\langle\begin{array}{llll}1 & 1 & 1\end{array}\right\rangle \quad$ is the experimentally observed system. The $\left\{\begin{array}{lllll}3 & 3 & 2\end{array}\right\}\left\langle\begin{array}{llll}1 & 1 & 3\end{array}\right\rangle$ system is generally activated when the SF values for $\left\{\begin{array}{lll}1 & 1 & 2\end{array}\right\}\left\langle\begin{array}{lll}1 & 1 & 1\end{array}\right\rangle$ are lower. Occasionally, some grains with high SF values for twinning are not deformed by twinning and are most probably only deformed by slip.

To explain this point, the highest value of SF among the 12 variants of the two twinning systems $\left\{\begin{array}{lll}1 & 1 & 2\end{array}\right\}\left\langle\begin{array}{lll}1 & 1 & 1\end{array}\right\rangle$ and $\left\{\begin{array}{llllll}3 & 3 & 2\end{array}\right\}\left\langle\begin{array}{llll}1 & 1 & 3\end{array}\right\rangle$ is drawn in Figure 3 as a function of the tensile direction. The highest SF values for the $\left\{\begin{array}{lll}1 & 1 & 2\end{array}\right\}\left\langle\begin{array}{llll}1 & 1 & 1\end{array}\right\rangle$ twinning system were obtained when the tensile direction was close to the $\left\langle\begin{array}{lll}1 & 0 & 0\end{array}\right\rangle$ direction of the parent crystal. The highest SF values for the $\left\{\begin{array}{llllll}3 & 3 & 2\end{array}\right\}\left\langle\begin{array}{llll}1 & 1 & 3\end{array}\right\rangle$ system were obtained for a tensile direction close to $\left\langle\begin{array}{lll}1 & 1 & 1\end{array}\right\rangle$. When the tensile direction was closer to $\left\langle\begin{array}{llll}1 & 1 & 1\end{array}\right\rangle$ the SF values of $\left\{\begin{array}{lll}1 & 1 & 2\end{array}\right\}\left\langle\begin{array}{llll}1 & 1 & 1\end{array}\right\rangle$ became weak while the SF values of $\left\{\begin{array}{lllll}3 & 3 & 2\end{array}\right\}\left\langle\begin{array}{llll}1 & 1 & 3\end{array}\right\rangle$ rose above 0.4 and this system was then activated. In this type of alloy crystal orientation versus tensile direction is the parameter allowing selection of the twinning system. Nevertheless, when both systems have an equivalent SF we have proved that $\left\{\begin{array}{lll}1 & 1 & 2\end{array}\right\}\left\langle\begin{array}{lll}1 & 1 & 1\end{array}\right\rangle$ is preferentially activated. Thus the critical resolved shear stress (CRSS) of the $\left\{\begin{array}{lll}1 & 1 & 2\end{array}\right\}\left\langle\begin{array}{lll}1 & 1 & 1\end{array}\right\rangle$ twinning system is slightly lower than the CRSS of the $\left\{\begin{array}{llllll}3 & 3 & 2\end{array}\right\}\left\langle\begin{array}{llll}1 & 1 & 3\end{array}\right\rangle$ twinning system. However, these values are very close. Selection of the twinning system by CRSS only occurs for specific grain orientations for which the SF values are equivalent for both systems. Indeed, the highest SF values of the two twinning systems cover complementary orientation domains (Fig. 3). As 
most of the grains have only one twinning system with high SF values, crystallographic orientation is thus the relevant parameter selection of the twinning system.

As a conclusion, the Schmid factor is shown to be a pertinent parameter to predict the nature of the activated twinning system and variant in each specific grain. Variant selection in the $\left\{\begin{array}{lll}1 & 1 & 2\end{array}\right\}\left\langle\begin{array}{lll}1 & 1 & 1\end{array}\right\rangle$ and $\left\{\begin{array}{lll}3 & 3 & 2\end{array}\right\}\left\langle\begin{array}{llll}1 & 1 & 3\end{array}\right\rangle$ twinning systems clearly obeys Schmid's law in this metastable $\beta$-titanium alloy, i.e. for each system the activated variant is that which has the highest SF. On the other hand, selection of the twinning system is also determined by the crystallographic orientation of the grain with respect to the tensile direction, with the difference that when the two systems have close and high SF values the $\left\{\begin{array}{lll}1 & 1 & 2\end{array}\right\}\left\langle\begin{array}{lll}1 & 1 & 1\end{array}\right\rangle$ system is activated, whereas the $\left\{\begin{array}{llllll}3 & 3 & 2\end{array}\right\}\left\langle\begin{array}{llll}1 & 1 & 3\end{array}\right\rangle$ system is activated when it alone has a high $\mathrm{SF}$ value. As a consequence, the existence of crystallographic texture in this type of alloy can lead to the preferential selection of one twinning system based only on the specific crystallographic orientation of the grains.

\section{Acknowledgements}

This research was funded within the framework of the Eurêka/MNT ERA-Net European Consortium Project "NanoBioAll" (E!4482): Advanced Metallic Biomaterials, Nanostructured, for Implantable Medical Devices.

\section{References}

[1] M. Niinomi, J. Mech. Behav. Biomed. Mater. 1 (2008) 30.

[2] T. Gloriant, G. Texier, F. Prima, D. Laillé, D.M. Gordin, I. Thibon, D. Ansel, Adv. Eng. Mater. 8 (2006) 961.

[3] H.Y. Kim, Y. Ikehara, J.I. Kim, H. Hosoda, S. Miyazaki, Acta Mater 54 (2006) 2419.

[4] E. Bertrand, T. Gloriant, D.M. Gordin, E. Vasilescu, P. Drob, C. Vasilescu, S.I. Drob, J. Mech. Behav. Biomed. Mater. 3 (2010) 559.

[5] R.H. Richman, The diversity of twinning in body-centred cubic structures, in: R.E. ReedHill, J.P. Hirth, H.C. Rogers (Eds.), Deformation twinning, Gordon and Breach science publishers, New-York, 1964, pp. 238-271.

[6] M. Oka, Y. Taniguchi, Metall. Trans. 10A (1979) 651.

[7] S. Hanada, O. Izumi, Metall. Trans. 17A (1986) 1409.

[8] T. Sawai, A. Hishinuma, J. Phys. Chem. Solids 66 (2005) 335. 
[9] S. Godet, L. Jiang, A.A. Luo, J.J. Jonas; Scr. Mater. 55 (2006) 1055.

[10] J.W. Christian, S. Mahajan, Prog. Mater. Sci. 38 (1995) 1. 

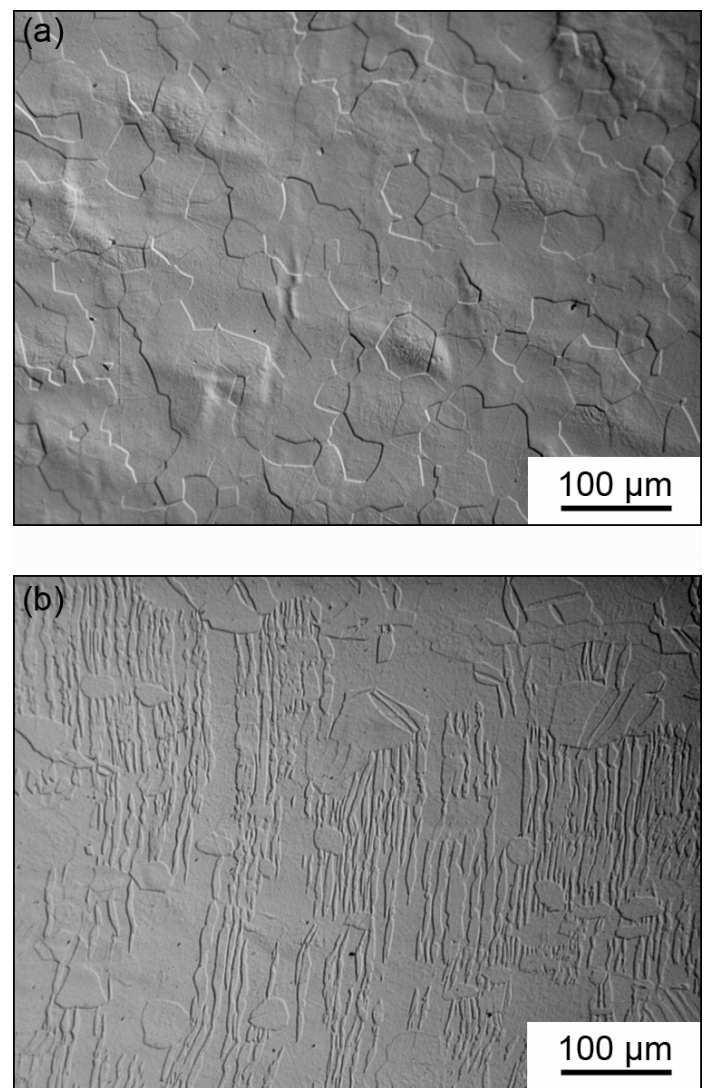

Figure 1. Optical micrographs of the microstructure before (a) and after (b) cyclic tensile test. 

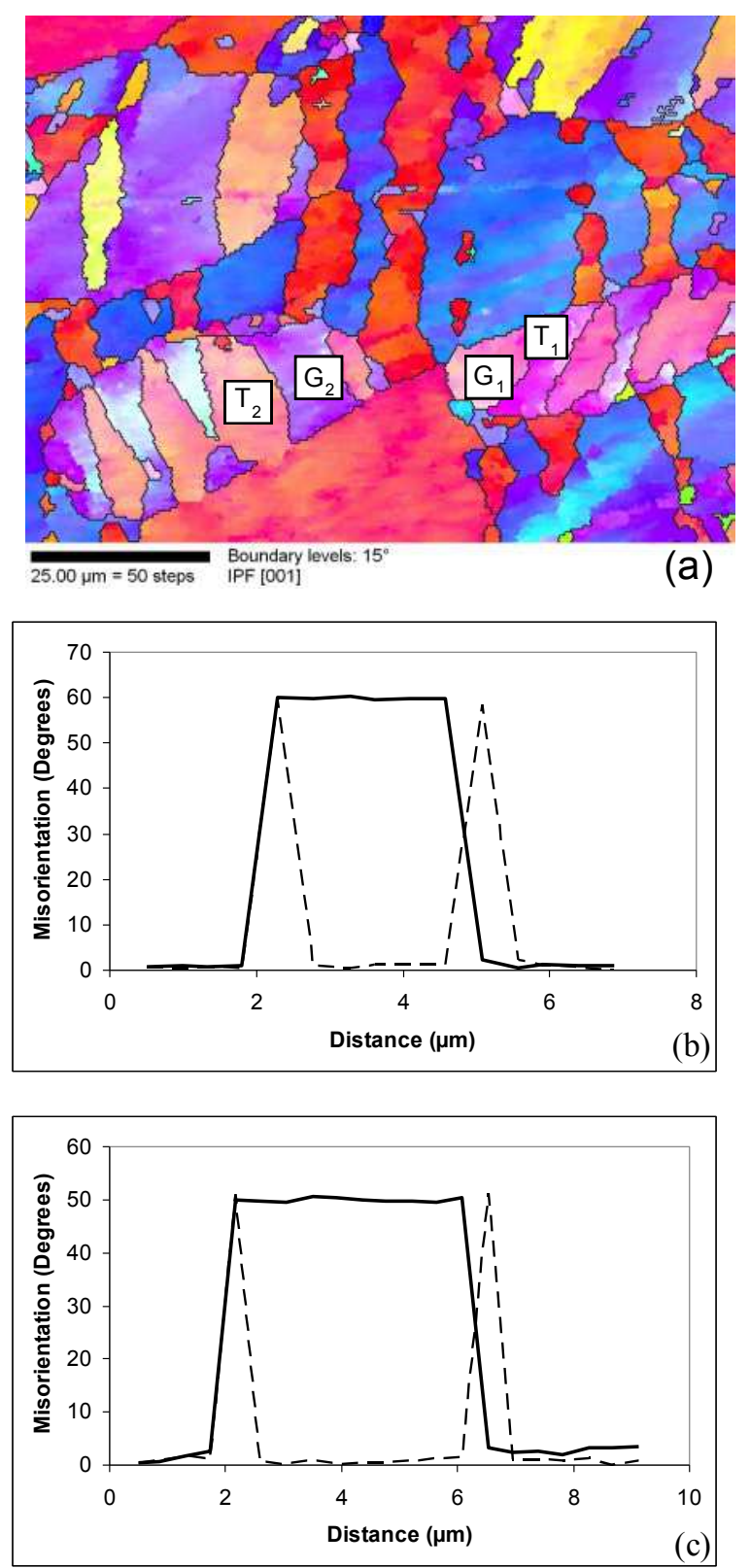

Figure 2. Inverse pole figure of Ti-25Ta-24Nb alloy after tensile test (a) and misorientation profiles between G1 and T1 (b) and between G2 and T2 (c) (solid line: point-to-origin dotted line: point-to-point). 


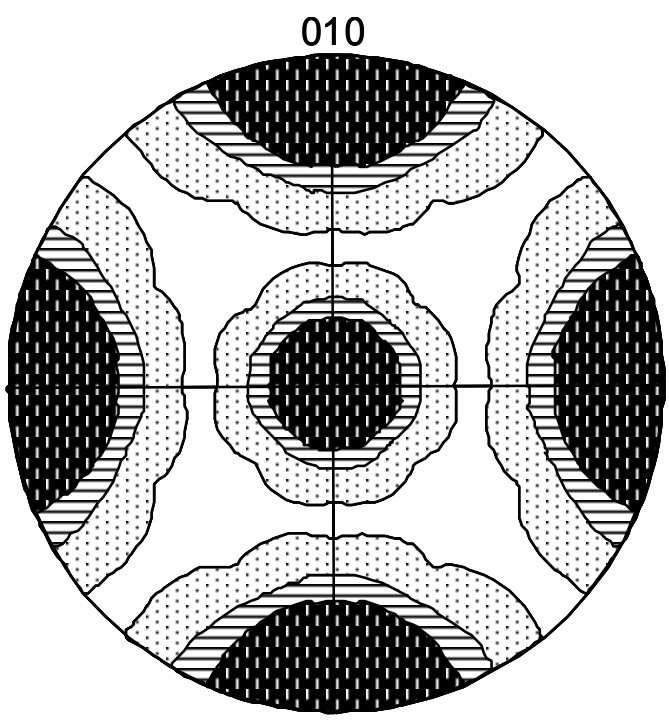

(a)

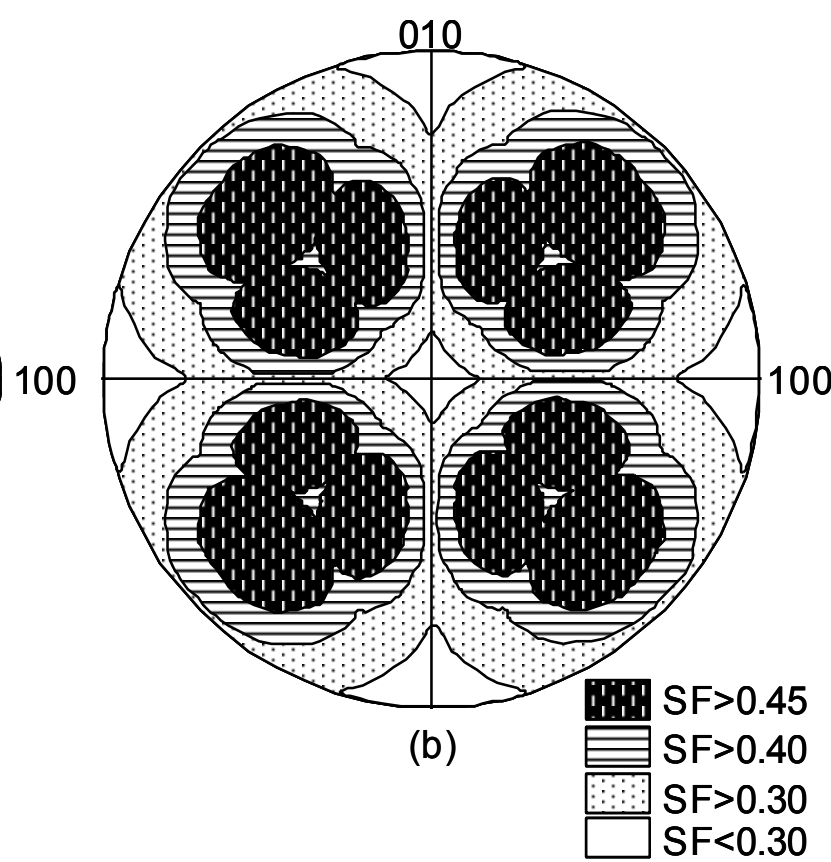

Figure 3. Maximum SF values as a function of the orientation of the tensile direction for the twelve variants of the two twinning systems $\{112\}<111>$ (a) and $\{332\}<113>$ (b). 
Table 1. The twelve variants from the $\{112\}<111>$ and $\{332\}<113>$ twinning systems

\begin{tabular}{c|c}
$\begin{array}{c}\{112\}<111> \\
\text { twinning system }\end{array}$ & $\begin{array}{c}\{332\}<113> \\
\text { twinning system }\end{array}$ \\
\hline$(112)[\overline{1} \overline{1} 1]$ & $(332)[11 \overline{3}]$ \\
$(121)[\overline{1} 1 \overline{1}]$ & $(323)[1 \overline{3} 1]$ \\
$(211)[1 \overline{1} \overline{1}]$ & $(233)[\overline{3} 11]$ \\
$(\overline{1} 12)[1 \overline{1} \overline{1}]$ & $(3 \overline{3} 2)[1 \overline{1} \overline{3}]$ \\
$(\overline{1} 21)[11 \overline{1}]$ & $(3 \overline{2} 3)[131]$ \\
$(\overline{2} 11)[\overline{1} \overline{1} \overline{1}]$ & $(2 \overline{3} 3)[\overline{3} \overline{1} 1]$ \\
$(1 \overline{1} 2)[\overline{1} 11]$ & $(\overline{3} 32)[\overline{1} 1 \overline{3}]$ \\
$(1 \overline{2} 1)[\overline{1} \overline{1} \overline{1}]$ & $(\overline{3} 23)[\overline{1} \overline{3} 1]$ \\
$(2 \overline{1} 1)[11 \overline{1}]$ & $(\overline{2} 33)[311]$ \\
$(11 \overline{2})[\overline{1} \overline{1} \overline{1}]$ & $(33 \overline{2})[113]$ \\
$(12 \overline{1})[\overline{1} 11]$ & $(32 \overline{3})[1 \overline{3} \overline{1}]$ \\
$(21 \overline{1})[1 \overline{1} 1]$ & $(23 \overline{3})[\overline{3} 1 \overline{1}]$
\end{tabular}


Table 2a. Twinning variants for which $|\mathrm{SF}|>0.3$ in grain G1. The bolded value of SF corresponds to the experimentally activated variant.

\begin{tabular}{c|ccc|c}
$\{112\}<111>$ & SF & & $\{332\}<113>$ & SF \\
\cline { 1 - 2 }$(121)[\overline{1} 1 \overline{1}]$ & $\mathbf{0 , 4 3}$ & & $(3 \overline{2} 3)[131]$ & $-0,49$ \\
\hline$(\overline{1} 21)[11 \overline{1}]$ & 0,38 & & $(\overline{3} 32)[\overline{1} 1 \overline{3}]$ & 0,41 \\
\hline$(1 \overline{1} 2)[\overline{1} 11]$ & $-0,40$ & & $(\overline{3} 23)[\overline{1} \overline{3} 1]$ & $-0,34$ \\
\hline$(2 \overline{1} 1)[11 \overline{1}]$ & $-0,37$ & & $(23 \overline{3})[\overline{3} 1 \overline{1}]$ & 0,40 \\
\hline$(12 \overline{1})[\overline{1} 11]$ & 0,40 & &
\end{tabular}

Table 2b. Twinning variants for which $|\mathrm{SF}|>0.3$ in grain G2. The bolded value of SF corresponds to the experimentally activated variant.

\begin{tabular}{|c|c|c|c|}
\hline$\{112\}<111>$ & SF & $\{332\}<113>$ & SF \\
\hline$(112)[\overline{1} \overline{1} 1]$ & $-0,49$ & $(323)[1 \overline{3} 1]$ & $-0,36$ \\
\hline \multirow[t]{2}{*}{$(11 \overline{2})[\overline{1} \overline{1} \overline{1}]$} & $-0,37$ & $(332)[113]$ & 0,48 \\
\hline & & $(32 \overline{3})[1 \overline{3} \overline{1}]$ & $-0,33$ \\
\hline
\end{tabular}

